\title{
Predicted thermochemistry and unimolecular kinetics of nitrous sulfide
}

\author{
Marshall, Paul; Gao, Yide; Glarborg, Peter
}

Published in:

Journal of Chemical Physics

Link to article, DOI:

$10.1063 / 1.3628521$

Publication date:

2011

Document Version

Publisher's PDF, also known as Version of record

Link back to DTU Orbit

Citation (APA):

Marshall, P., Gao, Y., \& Glarborg, P. (2011). Predicted thermochemistry and unimolecular kinetics of nitrous sulfide. Journal of Chemical Physics, 135(9), 094301. https://doi.org/10.1063/1.3628521

\section{General rights}

Copyright and moral rights for the publications made accessible in the public portal are retained by the authors and/or other copyright owners and it is a condition of accessing publications that users recognise and abide by the legal requirements associated with these rights.

- Users may download and print one copy of any publication from the public portal for the purpose of private study or research.

- You may not further distribute the material or use it for any profit-making activity or commercial gain

- You may freely distribute the URL identifying the publication in the public portal

If you believe that this document breaches copyright please contact us providing details, and we will remove access to the work immediately and investigate your claim. 


\title{
Predicted thermochemistry and unimolecular kinetics of nitrous sulfide
}

\author{
Paul Marshall, ${ }^{1, a)}$ Yide Gao, ${ }^{1}$ and Peter Glarborg ${ }^{2}$ \\ ${ }^{1}$ Department of Chemistry and Center for Advanced Scientific Computing and Modeling, University of North \\ Texas, 1155 Union Circle \#305070, Denton, Texas 76203-5017, USA \\ ${ }^{2}$ Department of Chemical and Biochemical Engineering, Technical University of Denmark, Building 229, \\ DK-2800 Kgs. Lyngby, Denmark
}

(Received 20 June 2011; accepted 5 August 2011; published online 1 September 2011)

\begin{abstract}
The geometry of $\mathrm{N}_{2} \mathrm{~S}$ was obtained at the $\mathrm{CCSD}(\mathrm{T}) /$ aug-cc-pV(T $\left.+\mathrm{d}\right) \mathrm{Z}$ level of theory and energies with coupled-cluster single double triple $(\operatorname{CCSD}(\mathrm{T}))$ and basis sets up to aug-cc-pV $(6+\mathrm{d}) \mathrm{Z}$. After correction for anharmonic zero-point energy, core-valence correlation, correlation up to CCSDT(Q) and relativistic effects, $\mathrm{D}_{0}$ for the $\mathrm{N}-\mathrm{S}$ bond is estimated as $71.9 \mathrm{~kJ} \mathrm{~mol}^{-1}$, and the corresponding thermochemistry for $\mathrm{N}_{2} \mathrm{~S}$ is $\Delta_{\mathrm{f}} \mathrm{H}_{0}^{\circ}=205.4 \mathrm{~kJ} \mathrm{~mol}^{-1}$ and $\Delta_{\mathrm{f}} \mathrm{H}_{298}^{\circ}=202.6 \mathrm{~kJ} \mathrm{~mol}^{-1}$ with an uncertainty of $\pm 2.5 \mathrm{~kJ} \mathrm{~mol}^{-1}$. Using $\operatorname{CCSD}(\mathrm{T}) /$ aug-cc-pV(T $\left.+\mathrm{d}\right)$ theory the minimum energy crossing point between singlet and triplet potential energy curves is found at $\mathrm{r}(\mathrm{N}-\mathrm{N}) \approx 1.105 \AA$ and $\mathrm{r}(\mathrm{N}-$ $\mathrm{S}) \approx 2.232 \AA$, with an energy $72 \mathrm{~kJ} \mathrm{~mol}^{-1}$ above $\mathrm{N}_{2}+\mathrm{S}\left({ }^{3} \mathrm{P}\right)$. Application of Troe's unimolecular formalism yields the low-pressure-limiting rate constant for dissociation of $\mathrm{N}_{2} \mathrm{~S} \mathrm{k}_{0}=7.6 \times 10^{-10}$ $\exp \left(-126 \mathrm{~kJ} \mathrm{~mol}^{-1} / \mathrm{RT}\right) \mathrm{cm}^{3}$ molecule $\mathrm{s}^{-1} \mathrm{~s}^{-1}$ over $700-2000 \mathrm{~K}$. The estimated uncertainty is a factor of 4 arising from unknown parameters for energy transfer between $\mathrm{N}_{2} \mathrm{~S}$ and $\mathrm{Ar}$ or $\mathrm{N}_{2}$ bath gas. The thermochemistry and kinetics were included in a mechanism for $\mathrm{CO} / \mathrm{H}_{2} / \mathrm{H}_{2} \mathrm{~S}$ oxidation and the conclusion is that little NO is produced via subsequent chemistry of NNS. ( 2011 American Institute of Physics. [doi:10.1063/1.3628521]
\end{abstract}

\section{INTRODUCTION}

The chemistry of nitrogen oxide formation in flames has been studied extensively ${ }^{1}$ and the major mechanisms are fairly well established. It is generally recognized that formation of $\mathrm{NO}_{\mathrm{x}}$ may arise from fixation of $\mathrm{N}_{2}$ in the combustion air or oxidation of organically bound nitrogen in the fuel. Homogeneous mechanisms for fixation of $\mathrm{N}_{2}$ involve the attack of reactive radicals $(\mathrm{O}, \mathrm{CH}, \mathrm{H})$ on the triple bond in molecular nitrogen. These reactions form either $\mathrm{NO}$ or a reactive nitrogen intermediate $\left(\mathrm{N}_{2} \mathrm{O}, \mathrm{NCN}\right.$, and $\left.\mathrm{NNH}\right)$ that may subsequently be oxidized to NO. Significant influences of small amounts of sulfur on the formation of nitrogen oxides have been observed at elevated temperatures, but the detailed mechanism is unknown. ${ }^{2}$ Here we consider possible roles for nitrous sulfide, $\mathrm{N}_{2} \mathrm{~S}$, the sulfur analog of $\mathrm{N}_{2} \mathrm{O}$, in order to evaluate the possibility of nitrogen fixation via reaction with atomic sulfur in flames.

The $\mathrm{N}_{2} \mathrm{~S}$ molecule has been observed via infrared spectroscopy in the gas-phase and in matrix isolation. ${ }^{3}$ It has been the object of several computational studies, ${ }^{4-6}$ with the main goal of interpreting the spectra, and which confirm linear NNS as the most stable structure. Here we present an $a b$ initio analysis of the thermochemistry of the $\mathrm{N}_{2} \mathrm{~S}$ molecule, and estimates of its unimolecular kinetics at elevated temperatures. Our aim is to check for the potential involvement of this species in the coupling of sulfur and nitrogen chemistry in flames and other high temperature systems. Analogous to the thermal decomposition of $\mathrm{N}_{2} \mathrm{O},{ }^{7,8}$ the dis-

\footnotetext{
${ }^{a)}$ Author to whom correspondence should be addressed. Electronic mail: marshall@unt.edu.
}

sociation

$$
\mathrm{N}_{2} \mathrm{~S} \rightarrow \mathrm{N}_{2}+\mathrm{S}
$$

is spin-forbidden, and we expect the kinetics of reaction (1) to be similarly controlled by crossing between the singlet potential energy curve for the reactant and the triplet potential energy curve for the products. ${ }^{9}$ In the case of $\mathrm{N}_{2} \mathrm{O}$ the triplet interaction is repulsive so intersystem crossing occurs at an energy significantly above the dissociation energy of $\mathrm{N}_{2} \mathrm{O}$ to ground state products. ${ }^{10}$ The $0 \mathrm{~K}$ bond dissociation enthalpy of $\mathrm{N}_{2} \mathrm{O}$ is $161 \mathrm{~kJ} \mathrm{~mol}^{-1}$ while the activation energy for its dissociation is some $100 \mathrm{~kJ} \mathrm{~mol}^{-1}$ higher at the high-pressure limit. ${ }^{8}$ Several theoretical studies have focused on the spinforbidden dissociation of $\mathrm{N}_{2} \mathrm{O}$ (see Refs. 10-12 and references therein).

Here we map out the lowest energy singlet and triplet potential energy surfaces for $\mathrm{N}_{2} \mathrm{~S}$ and use the results to address the thermochemistry of this molecule, and to make predictions of its unimolecular reaction kinetics and its potential role in combustion. Energy transfer parameters for $\mathrm{N}_{2} \mathrm{~S}$ are estimated by analogy to the valence isoelectronic species $\mathrm{N}_{2} \mathrm{O}$ and carbonyl sulfide OCS, for which dissociation measurements are available.

\section{METHODOLOGY}

Initial analysis of linear $\mathrm{N}_{2} \mathrm{~S}$ in the singlet ${ }^{1} \Sigma^{+}$and triplet ${ }^{3} \Pi$ states was carried out using coupled-cluster single double triple $(\operatorname{CCSD}(\mathrm{T}))$ theory ${ }^{13}$ and the aug-cc-pV(T $\left.+\mathrm{d}\right) \mathrm{Z}$ basis set which includes "tight d" functions on sulfur ${ }^{14}$ (and not nitrogen, for which this basis is equal to aug-cc-pVTZ (Refs. 15 and 16)). For the singlet species, spin-restricted Hartree-Fock 
TABLE I. Ab initio energies for the $\mathrm{N}_{2} \mathrm{~S}$ system (all quantities in a.u. unless otherwise noted, 1 a.u. $\approx 2625.5 \mathrm{~kJ} \mathrm{~mol}^{-1}$ ).

\begin{tabular}{|c|c|c|c|c|c|c|c|c|}
\hline \multirow[b]{2}{*}{ Species } & \multicolumn{4}{|c|}{$\operatorname{CCSD}(T)$ energies with aug-cc-pV $(n+d) Z$ basis sets } & \multirow[b]{2}{*}{$\mathrm{ZPE} \mathrm{E}^{\mathrm{a}}$} & \multirow{2}{*}{$\begin{array}{l}\text { Scalar rel- } \\
\text { ativistic }^{\text {b }}\end{array}$} & \multirow{2}{*}{$\begin{array}{c}\text { Core } \\
\text { valence }^{\mathrm{c}}\end{array}$} & \multirow{2}{*}{$\begin{array}{c}\operatorname{CCSDT}(\mathrm{Q})- \\
\operatorname{CCSD}(\mathrm{T})^{\mathrm{d}}\end{array}$} \\
\hline & $\mathrm{AV}(\mathrm{T}+\mathrm{d}) \mathrm{Z}$ & $A V(Q+d) Z$ & $\mathrm{AV}(5+\mathrm{d}) \mathrm{Z}$ & $\operatorname{AV}(6+d) Z$ & & & & \\
\hline $\mathrm{N}_{2}$ & -109.38085 & -109.40721 & -109.41546 & -109.41833 & 1176 & -0.05829 & -0.12119 & -0.00155 \\
\hline S & -397.65722 & -397.66862 & -397.67210 & -397.67356 & 0 & -1.07746 & -0.42866 & -0.00088 \\
\hline $\mathrm{N}_{2} \mathrm{~S}$ & -507.06330 & -507.10443 & -507.11725 & -507.12200 & 1884 & -1.13488 & -0.55051 & -0.00360 \\
\hline$\Delta \mathrm{E}^{\mathrm{e}}$ & 66.26 & 75.09 & 77.96 & 79.07 & -8.47 & -2.30 & 1.75 & 3.10 \\
\hline
\end{tabular}

${ }^{\mathrm{a}}$ In $\mathrm{cm}^{-1}$ (see text).

${ }^{\mathrm{b}} \mathrm{Sum}$ of mass-velocity and Darwin terms at CISD/cc-pwCVTZ level.

${ }^{\mathrm{c}} \mathrm{CCSD}(\mathrm{T}) / \mathrm{cc}$-pwCVTZ and CCSD(T)/cc-pwCVQZ data were extrapolated to the CBS limit via Eq. (2), and the difference taken between including a frozen core or using all the electrons in the correlation calculations.

${ }^{\mathrm{d}}$ Calculated with the cc-pVTZ basis set.

${ }^{\mathrm{e}}$ Contribution to energy change for reaction (1) in $\mathrm{kJ} \mathrm{mol}^{-1}$

and $\operatorname{CCSD}(\mathrm{T})$ was employed, and spin-unrestricted versions were used for the triplet species. Spin contamination was negligible, with $\left\langle\mathrm{S}^{2}\right\rangle$ below 2.03 for the triplet states, which compares well with the ideal value of 2 . The geometries of singlet $\mathrm{N}_{2} \mathrm{~S}$ and $\mathrm{N}_{2}$ were optimized. Then $\mathrm{r}(\mathrm{N}-\mathrm{N})$ in the linear $\mathrm{N}_{2} \mathrm{~S}$ configuration was optimized as a function of various fixed $\mathrm{N}-\mathrm{S}$ separations, in both singlet and triplet states, to explore the singlet and triplet potential energy curves. These computations were carried out with the GAUSSIAN 03 program suite. $^{17}$

The MOLPRO 2006 program $^{18}$ was used to derive the $\mathrm{N}$ $-\mathrm{S}$ bond dissociation enthalpy in $\mathrm{N}_{2} \mathrm{~S}$. At the CCSD(T)/augcc-pV(T $+d) Z$ geometries, energies of singlet $\mathrm{N}_{2} \mathrm{~S}$, singlet $\mathrm{N}_{2}$, and triplet $\mathrm{S}$ were obtained with a sequence of aug-cc$\mathrm{pV}(\mathrm{n}+\mathrm{d}) \mathrm{Z}$ basis sets with $\mathrm{n}=3-6$ and $\operatorname{CCSD}(\mathrm{T})$ theory $(\operatorname{RCCSD}(\mathrm{T})$ for the closed shell species and UCCSD(T) (Ref. 19) for atomic sulfur, all with spin-restricted HartreeFock wave functions). Core-valence correlation was assessed with CCSD(T)/cc-pwCVTZ theory ${ }^{20}$ as the difference between the energy with all electrons correlated and with the core electrons frozen. Convergence of this contribution was investigated by carrying out CCSD(T)/cc-pwCVQZ calculations as well. Scalar relativistic effects were incorporated at the CISD/cc-pwCVTZ level as the sum of the mass-velocity and Darwin terms, ${ }^{21}$ and vector relativistic effects were included via the experimental spin-orbit splitting of the ${ }^{3} \mathrm{P}$ state of atomic sulfur ${ }^{22}\left(-2.35 \mathrm{~kJ} \mathrm{~mol}^{-1}\right)$. The MRCC program by Kállay $^{23}$ interfaced to the CFOUR code ${ }^{24}$ was employed to test the effect of higher level electron correlation by means of $\operatorname{CCSD}(\mathrm{T})$ and $\operatorname{CCSDT}(\mathrm{Q})$ calculations with the cc-pVTZ basis set. ${ }^{15,25}$

\section{RESULTS AND DISCUSSION}

\section{A. Geometry and thermochemistry}

Our $r_{e}$ for $\mathrm{N}_{2}$ at the CCSD(T)/aug-cc-pVTZ level of theory is $1.104 \AA\left(1 \AA=10^{-10} \mathrm{~m}\right)$, which is $0.006 \AA$ greater than the experimental value. ${ }^{26}$ Combined with the force constant this bond extension would lead to an energy $\sim 0.3 \mathrm{~kJ} \mathrm{~mol}^{-1}$ too high relative to the minimum. For $\mathrm{N}_{2} \mathrm{~S}$, our CCSD(T)/augcc-pV $(\mathrm{T}+\mathrm{d})$ computation for $\mathrm{r}_{\mathrm{e}}(\mathrm{N}-\mathrm{N})$ of $1.132 \AA$ is $0.001 \AA$ above the best estimate of Pak et al., ${ }^{6}$ which would induce a negligible energy error, less than $0.02 \mathrm{~kJ} \mathrm{~mol}^{-1}$. It has been noted previously that $\mathrm{r}_{\mathrm{e}}(\mathrm{N}-\mathrm{S})$ tends to be overestimated, 5,6 and indeed our $r_{e}(\mathrm{~N}-\mathrm{S})$ of $1.593 \AA$ is somewhat too high, and lies $0.015 \AA$ above the best estimate of Pak et al. ${ }^{6}$ Coupled with the N-S stretching force constant this will lead to an energy error of $+0.3 \mathrm{~kJ} \mathrm{~mol}^{-1}$, and therefore there is fortuitous cancellation of the contributions of geometry errors to the $\mathrm{N}_{2}-\mathrm{S}$ bond dissociation enthalpy.

Table I summarizes the $a b$ initio data for $\mathrm{N}_{2} \mathrm{~S}, \mathrm{~N}_{2}$, and $\mathrm{S}$, and the equilibrium $\mathrm{N}_{2}-\mathrm{S}$ dissociation energy $\mathrm{D}_{\mathrm{e}}$ (shown as $\Delta \mathrm{E}$ in the first four columns) which does not include zeropoint vibrational energy. It may be seen that application of large basis sets has almost but not quite converged $D_{e}$. Several functions have been proposed for extrapolation of individual energies to the infinite or complete basis set (CBS) limit, as a function of an index $\mathrm{n}$ which varied from 3 in the aug-cc-pV $(\mathrm{T}+\mathrm{d}) \mathrm{Z}$ basis set through 6 in the aug-cc-pV(6 $+\mathrm{d}) \mathrm{Z}$ basis. We have employed the two-point relationship of Helgaker et al., ${ }^{27}$

$$
\mathrm{E}_{\mathrm{n}}=\mathrm{E}_{\mathrm{CBS}}+\frac{\mathrm{B}}{\mathrm{n}^{3}}
$$

the exponential relation of Feller ${ }^{28}$ fitted through three points

$$
\mathrm{E}_{\mathrm{n}}=\mathrm{E}_{\mathrm{CBS}}+\mathrm{B} \exp (-\mathrm{Cn})
$$

and the function of Martin ${ }^{29}$ fitted through all four points

$$
E_{n}=E_{C B S}+\frac{B}{(n+0.5)^{4}}+\frac{C}{(n+0.5)^{6}}
$$

to extrapolate the total energies (Hartree-Fock plus correlation). The CBS results are shown in Table II. The possible extrapolations involving the largest basis set $(n=6)$ are Eq. (2) applied to $\mathrm{n}=5$ and 6 , Eq. (3) with $\mathrm{n}=4-6$, and Eq. (4) (which we fitted to $\mathrm{n}=3-6$ ). They lead to $\mathrm{D}_{\mathrm{e}}=80.58$, 79.62 , and $80.23 \mathrm{~kJ} \mathrm{~mol}^{-1}$, respectively. The mean and standard deviation of these three values are 80.1 and $0.4 \mathrm{~kJ} \mathrm{~mol}^{-1}$, respectively. We note that the result of Eq. (4) lies in the middle. The two-point scheme with successively larger basis sets approaches this value from above while the two exponential scheme approaches this value from below (see Table II). These trends suggest that the true infinite basis set limit has been bracketed. Error limits of twice the standard deviation should conservatively encompass any uncertainty in the extrapolation. We can use this $\mathrm{D}_{\mathrm{e}}$ result to comment on extrapolations relying on smaller basis sets which of course are 
TABLE II. Extrapolation of ab initio energies for the $\mathrm{N}_{2} \mathrm{~S}$ system to the complete basis set limit (all quantities in a.u. unless otherwise noted, 1 a.u. $\approx 2625.5 \mathrm{~kJ} \mathrm{~mol}^{-1}$ ).

\begin{tabular}{lcccccc}
\hline \hline & \multicolumn{5}{c}{ Extrapolated CBS energies } \\
\cline { 2 - 7 } Species & $\mathrm{T}^{2} \mathrm{Q}^{\mathrm{a}}$ & $\mathrm{Q}^{\mathrm{a}} 5^{\mathrm{a}}$ & $5-6^{\mathrm{a}}$ & T-6 $^{\mathrm{b}}$ & T-5 $^{\mathrm{c}}$ & $\mathrm{Q}^{\mathrm{c}} 6^{\mathrm{c}}$ \\
\hline $\mathrm{N}_{2}$ & -109.42645 & -109.42411 & -109.42227 & -109.42186 & -109.41921 & -109.41986 \\
$\mathrm{~S}$ & -397.67694 & -397.67575 & -397.67556 & -397.67500 & -397.67363 & -397.67461 \\
$\mathrm{~N}_{2} \mathrm{~S}$ & -507.13445 & -507.13070 & -507.12852 & -507.12758 & -507.12305 & -507.12479 \\
$\Delta \mathrm{E}^{\mathrm{d}}$ & 81.53 & 80.98 & 80.58 & 80.23 & 79.34 & 79.62 \\
\hline \hline
\end{tabular}

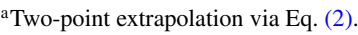

${ }^{b}$ Extrapolation via Eq. (4) fitted to four points.

${ }^{\mathrm{c}}$ Three-point extrapolation via Eq. (3).

${ }^{\mathrm{d}}$ Contribution to energy change for reaction (1) in $\mathrm{kJ} \mathrm{mol}^{-1}$.

dramatically more economical in terms of computer resources. The two-point 3-4 and 4-5 extrapolations give $\mathrm{D}_{\mathrm{e}}$ $=81.5$ and $81.0 \mathrm{~kJ} \mathrm{~mol}^{-1}$, and the exponential extrapolation based on $\mathrm{n}=3-5$ yields $\mathrm{D}_{\mathrm{e}}=79.3 \mathrm{~kJ} \mathrm{~mol}^{-1}$. These results indicate that for accuracy to within $2 \mathrm{~kJ} \mathrm{~mol}^{-1}$, calculations with up to $\operatorname{CCSD}(\mathrm{T}) /$ aug-cc-pV(Q $+\mathrm{d}) \mathrm{Z}$ and a two-point extrapolation would be adequate for the present system.

The core-valence correction to reaction (1) was found to be $1.96 \mathrm{~kJ} \mathrm{~mol}^{-1}$ with the cc-pwCVTZ basis set, and $1.84 \mathrm{~kJ} \mathrm{~mol}^{-1}$ with the cc-pwCVQZ basis set, so it is almost converged with respect to basis set size. The data in Table I were obtained by extrapolating the frozen-core and all-electron results with each basis set to the CBS limit by means of the two-point relation (2), and yield an estimated core-valence correction of $1.75 \mathrm{~kJ} \mathrm{~mol}^{-1}$ at the CBS limit. The equilibrium $D_{e}$ is then corrected (see Table I) for the core-valence and scalar relativistic effects (which almost cancel), the spin-orbit correction of atomic $\mathrm{S}\left({ }^{3} \mathrm{P}\right)$, the effect of correlation beyond the $\operatorname{CCSD}(\mathrm{T})$ level, and the anharmonic zero-point energy of $\mathrm{N}_{2}$ (Ref. 26) and $\mathrm{N}_{2} \mathrm{~S}^{6}{ }^{6}$ to obtain $\mathrm{D}_{\mathrm{o}}$ $=71.9 \mathrm{~kJ} \mathrm{~mol}^{-1}$. For comparison, this is less than half $\mathrm{D}_{\mathrm{o}}$ for $\mathrm{N}_{2}-\mathrm{O} .^{30}$ The tabulated heat of formation of atomic $\mathrm{S}$ is $274.9 \mathrm{~kJ} \mathrm{~mol}^{-1}$ at $0 \mathrm{~K},{ }^{31}$ but Nagy et al..$^{32}$ recently argued for revision to $277.3 \mathrm{~kJ} \mathrm{~mol}^{-1}$. We use the latter value plus tabulated thermal corrections for $\mathrm{S}$ and $\mathrm{N}_{2},{ }^{31}$ and $\mathrm{H}_{298}-\mathrm{H}_{0}$ $=10.26 \mathrm{~kJ} \mathrm{~mol}^{-1}$ computed here for $\mathrm{N}_{2} \mathrm{~S}$ from the fundamental frequencies recommended by Pak et al., ${ }^{6}$ to obtain $\Delta_{\mathrm{f}} \mathrm{H}_{0}^{\circ}$ $=205.4 \mathrm{~kJ} \mathrm{~mol}^{-1}$ for $\mathrm{N}_{2} \mathrm{~S}$, and $\Delta_{\mathrm{f}} \mathrm{H}_{298}^{\circ}=202.6 \mathrm{~kJ} \mathrm{~mol}^{-1}$. The $\Delta_{\mathrm{f}} \mathrm{H}_{0}^{\circ}(\mathrm{S})$ has a quoted uncertainty of $0.3 \mathrm{~kJ} \mathrm{~mol}^{-1}$ so the estimated uncertainty in the thermochemistry is $\pm 0.8 \mathrm{~kJ} \mathrm{~mol}^{-1}$ arising mainly from uncertainty in the CBS extrapolations. This does not include any allowance for correlation effects beyond perturbative quadruples or whether the new $\Delta_{\mathrm{f}} \mathrm{H}_{0}^{\circ}(\mathrm{S})$ will be accepted generally. We note that in the computational work by Nagy et al.,$^{32}$ which also involves sulfur species and to which our approach is broadly similar, typical uncertainties in enthalpy were around $2-3 \mathrm{~kJ} \mathrm{~mol}^{-1}$ so we propose $\pm 2.5 \mathrm{~kJ} \mathrm{~mol}^{-1}$ as the overall uncertainty in the heat of formation.

A seven-term NASA polynomial ${ }^{33}$ fitted to computed thermodynamic functions over 100-3000 K, suitable for use in standard modeling codes, has the following coefficients $a_{1}-a_{7}: 2.99418214 \times 10^{0}, 9.00692800 \times 10^{-3}$, $-7.39316000 \times 10^{-6}, 2.67928000 \times 10^{-9},-3.51975000$ $\times 10^{-13}, 2.31452584 \times 10^{4}$, and $8.59332874 \times 10^{0}$. With these coefficients, the heat capacity is given by

$$
\frac{C_{p}}{R}=a_{1}+a_{2} T+a_{3} T^{2}+a_{4} T^{3}+a_{5} T^{4},
$$

the entropy is given by

$$
\frac{\mathrm{S}}{\mathrm{R}}=\mathrm{a}_{1} \ln \mathrm{T}+\mathrm{a}_{2} \mathrm{~T}+\frac{\mathrm{a}_{3} \mathrm{~T}^{2}}{2}+\frac{\mathrm{a}_{4} \mathrm{~T}^{3}}{3}+\frac{\mathrm{a}_{5} \mathrm{~T}^{4}}{4}+\mathrm{a}_{7},
$$

and the enthalpy, defined as $\mathrm{H}=\Delta_{\mathrm{f}} \mathrm{H}_{298.15}+\left(\mathrm{H}_{\mathrm{T}}-\mathrm{H}_{298.15}\right)$, is given by

$$
\frac{H}{R T}=a_{1}+\frac{a_{2} T}{2}+\frac{a_{3} T^{2}}{3}+\frac{a_{4} T^{3}}{4}+\frac{a_{5} T^{4}}{5}+\frac{a_{6}}{T} .
$$

\section{B. Kinetics}

Figure 1 shows the singlet and triplet potential energy curves for linear $\mathrm{N}_{2} \mathrm{~S}$ as a function of $\mathrm{r}(\mathrm{N}-\mathrm{S})$. It may be seen that the triplet system is purely repulsive, as expected by analogy with the well-studied $\mathrm{N}_{2} \mathrm{O}$ system. ${ }^{10}$ The singlet curve shown dissociates to $\mathrm{N}_{2}+{ }^{1} \mathrm{~S}$. The wave function for these products would require a multi-reference description, but the T1 diagnostic for the singlet state near the crossing is below 0.02 and so $\operatorname{CCSD}(\mathrm{T})$ based on a single-reference wave function should be adequate in this region. ${ }^{34}$ The intersection

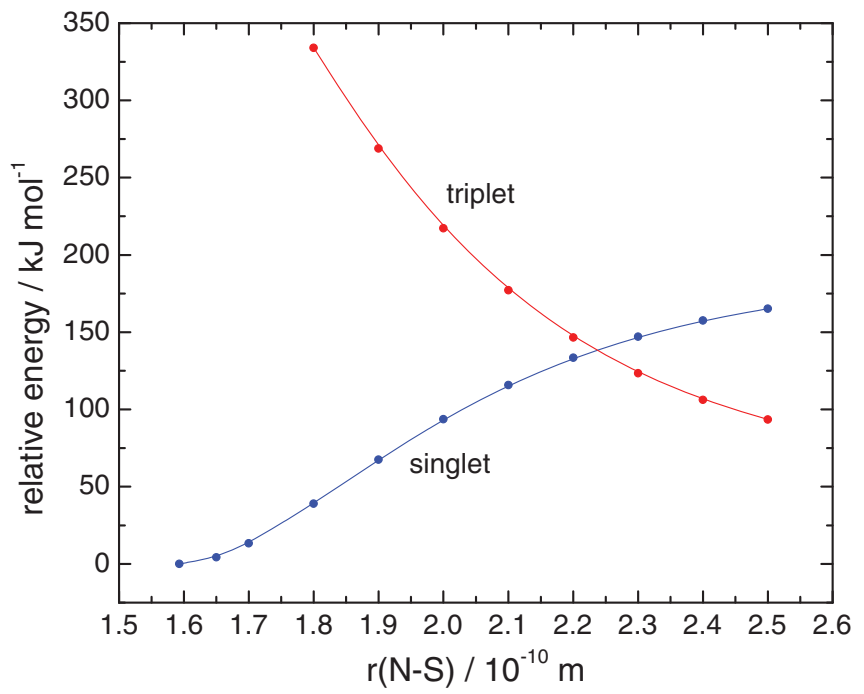

FIG. 1. $\operatorname{CCSD}(\mathrm{T}) /$ aug-cc-pV(T $+\mathrm{d}) \mathrm{Z}$ energies of singlet and triplet linear $\mathrm{N}_{2} \mathrm{~S}$ as a function of $\mathrm{N}-\mathrm{S}$ distance, relative to the singlet $\mathrm{N}_{2} \mathrm{~S}$ minimum. The $\mathrm{N}-\mathrm{N}$ distance has been optimized at each point. 
of the curves in Fig. 1 approximately indicates the region of intersystem crossing, although the $\mathrm{N}-\mathrm{N}$ distances are slightly different. Trial and error indicates that the minimum energy crossing point $(\mathrm{MECP})$ occurs near $\mathrm{r}(\mathrm{N}-\mathrm{N}) \approx 1.105 \AA$ and $\mathrm{r}(\mathrm{N}-\mathrm{S}) \approx 2.232 \AA$, and that both singlet and triplet states at this geometry lie within $0.2 \mathrm{~kJ} \mathrm{~mol}^{-1}$ of each other and about $72 \mathrm{~kJ} \mathrm{~mol}^{-1}$ above $\mathrm{N}_{2}+\mathrm{S}\left({ }^{3} \mathrm{P}\right)$. The MECP is therefore $144 \mathrm{~kJ} \mathrm{~mol}^{-1}$ above the $\mathrm{v}=0$ level of $\mathrm{N}_{2} \mathrm{~S}$. For comparison, in the case of the $\mathrm{N}_{2} \mathrm{O}=\mathrm{N}_{2}+{ }^{3} \mathrm{O}$ system the QCISD(T) study of Hwang and Mebel yielded a MECP geometry with $\mathrm{r}(\mathrm{N}-\mathrm{N})$ $=1.106 \AA$ and $\mathrm{r}(\mathrm{N}-\mathrm{O})=1.787 \AA$ lying $97 \mathrm{~kJ} \mathrm{~mol}^{-1}$ above separated $\mathrm{N}_{2}+\mathrm{O}\left({ }^{3} \mathrm{P}\right) .{ }^{12}$

We treat the kinetics of reaction (1) via RiceRamsperger-Kassel-Marcus (RRKM) theory. At the low pressure limit the populations of energy levels of $\mathrm{N}_{2} \mathrm{~S}$ at the MECP will be controlled by the balance between $k_{1}(\mathrm{E})$ and $\mathrm{k}_{-1}(\mathrm{E})$, and in this microcanonical equilibrium the probability of intersystem crossing (which affects both rate processes equally) cancels. The low-pressure limit $\mathrm{k}_{1,0}$ is therefore independent of any assumptions about intersystem crossing, ${ }^{9,35}$ but does depend critically on the energy of the MECP, and can be treated as a normal reaction via RRKM theory. We will apply Troe's unimolecular formalism ${ }^{36}$ to derive $\mathrm{k}_{1,0}$ via

$$
\mathrm{k}_{1,0}=\mathrm{Z}_{\mathrm{LJ}} \beta_{\mathrm{c}} \frac{\rho_{\mathrm{vib}}\left(\mathrm{E}_{0}\right) \mathrm{RT}}{\mathrm{Q}_{\mathrm{vib}}} \exp \left(-\frac{\mathrm{E}_{0}}{\mathrm{RT}}\right) \mathrm{F}_{\mathrm{E}} \mathrm{F}_{\mathrm{anh}} \mathrm{F}_{\text {rot }}
$$

with energies expressed in $\mathrm{J} \mathrm{mol}^{-1}$. The various quantities follow the standard notation. $\mathrm{E}_{0}$ is the threshold energy for dissociation, i.e., the $0 \mathrm{~K}$ bond dissociation enthalpy plus the energy of the MECP relative to the fragments. We first consider application of Troe's formalism to two isoelectronic analogs of reaction (1), the dissociations of $\mathrm{N}_{2} \mathrm{O}$ and OCS, where experimental data are available.

For OCS our scans of the triplet and singlet surfaces, conducted as described for $\mathrm{N}_{2} \mathrm{~S}$, lead to a MECP at $\mathrm{r}(\mathrm{C}-\mathrm{O})$ $=1.136 \AA$ and $\mathrm{r}(\mathrm{C}-\mathrm{S})=2.405 \AA$, with an energy $35 \mathrm{~kJ} \mathrm{~mol}^{-1}$ above $\mathrm{CO}+\mathrm{S}\left({ }^{3} \mathrm{P}\right)$. These data imply a threshold energy of $\mathrm{E}_{0}=337 \mathrm{~kJ} \mathrm{~mol}^{-1}$ and the ratio of the moments of inertia of the MECP to the molecule of $\mathrm{I}^{+} / \mathrm{I}=1.77$. Lennard-Jones (LJ) parameters for the OCS molecule were estimated from its critical properties to be $\sigma=4.55 \AA$ and $\epsilon / \mathrm{k}_{\mathrm{B}}=289 \mathrm{~K}$ and parameters for Ar were taken from the literature, ${ }^{37}$ in order to estimate the Lennard-Jones collision rate $Z_{\mathrm{LJ}}$. Evaluation of Eq. (5) with the collision efficiency $\beta_{\mathrm{c}}$ set to 1 yields the strong collision dissociation rate constant $\mathrm{k}_{\text {diss }, 0, \mathrm{SC}}$. This will be higher than that observed because typically several collisions with bath gas molecules are required to transfer sufficient energy to reactant molecules to exceed the dissociation threshold. The collision efficiency can be evaluated as $\mathrm{k}_{\text {expt }} / \mathrm{k}_{\mathrm{diss}, 0, \mathrm{SC}}$. Comparison with experimental data for OCS dissociation in Ar bath gas ${ }^{38}$ shows that $\beta_{\mathrm{c}}$ decreases from 0.058 at $2000 \mathrm{~K}$ to 0.024 at $3000 \mathrm{~K}$. The corresponding average energy transferred per collision $-\langle\Delta \mathrm{E}\rangle$ is derived via the relation $^{36}$

$$
\frac{\beta_{c}}{1-\beta_{c}^{1 / 2}}=\frac{-\langle\Delta \mathrm{E}\rangle}{\mathrm{F}_{\mathrm{E}} \mathrm{k}_{\mathrm{B}} \mathrm{T}}
$$

to obtain $-\langle\Delta \mathrm{E}\rangle$ values around $1 \mathrm{~kJ} \mathrm{~mol}^{-1}$.
For $\mathrm{N}_{2} \mathrm{O}$ in an $\mathrm{N}_{2}$ bath gas, Endo et al. derived $\beta_{\mathrm{c}}=0.043$ and 0.023 at 900 and $2000 \mathrm{~K}$, respectively, and thus $-\langle\Delta \mathrm{E}\rangle$ $=0.44$ and $0.54 \mathrm{~kJ} \mathrm{~mol}^{-1} .{ }^{39}$ They also suggested that $\mathrm{N}_{2}$ was a slightly more efficient collider than Ar, by factors of 1.26 and 1.05 at 900 and $2000 \mathrm{~K}$. We therefore expect that the collision efficiency for OCS in $\mathrm{N}_{2}$ is likely to be similar to that for $\mathrm{Ar}$ (in the context of the other uncertainties involved).

For reaction (1) at the low-pressure limit in $\mathrm{N}_{2}$ bath gas we used $\mathrm{E}_{0}=144 \mathrm{~kJ} \mathrm{~mol}^{-1}$ relative to the $\mathrm{v}=0$ level of $\mathrm{N}_{2} \mathrm{~S}$, and vibrational frequencies of $463,463,741$, and $2061 \mathrm{~cm}^{-1}$. The Lennard-Jones parameters for $\mathrm{N}_{2} \mathrm{~S}$ were assumed to be the same as for the similar OCS molecule, and the parameters for $\mathrm{N}_{2}$ as a bath gas were taken from Hippler et al. ${ }^{37} \mathrm{We}$ assumed $-\langle\Delta \mathrm{E}\rangle$ provisionally to be independent of temperature and set it equal to $0.5 \mathrm{~kJ} \mathrm{~mol}^{-1}$. This implies $\beta_{\mathrm{c}}$ of 0.04 at $1000 \mathrm{~K}$ decreasing to 0.02 at $2000 \mathrm{~K}$. The geometry at the MECP yields a moment of inertia 1.60 times larger than for $\mathrm{N}_{2} \mathrm{~S}$, which is used as the ratio $\mathrm{I}^{+} / \mathrm{I}$ to calculate the centrifugal correction $\mathrm{F}_{\text {rot }}$ for this linear system. ${ }^{36}$ The results from Eq. (5) can be summarized as

$\mathrm{k}_{1,0}=7.6 \times 10^{-10} \exp \left(\frac{-126 \mathrm{~kJ} \mathrm{~mol}^{-1}}{\mathrm{RT}}\right) \mathrm{cm}^{3}$ molecule $^{-1} \mathrm{~s}^{-1}$

over $700-2000 \mathrm{~K}$.

An uncertainty of a factor of 4 arises from uncertainty in the energy transfer parameters and the $\mathrm{F}_{\text {rot }}$ term, but this rough estimate permits an initial evaluation of $\mathrm{N}_{2} \mathrm{~S}$ behavior at high temperatures.

Equation (6) is the low-pressure-limiting rate constant which for a small molecule like $\mathrm{N}_{2} \mathrm{~S}$ should be applicable over typical pressures. To explore the range of validity some assessment of the high-pressure-limiting kinetics is needed, which are sensitive to the probability of intersystem crossing. We employ the $\mathrm{N}_{2} \mathrm{O}$ analog to set a lower limit to the pressure range where Eq. (6) can reasonably be applied. The experimental high-pressure limit for $\mathrm{N}_{2} \mathrm{O}$ dissociation is $\mathrm{k}_{\infty}$ $=1.3 \times 10^{13} \exp \left(-262 \mathrm{~kJ} \mathrm{~mol}^{-1} / \mathrm{RT}\right) \mathrm{s}^{-1} .{ }^{8}$ The activation energy $E_{a}$ is only $4 \mathrm{~kJ} \mathrm{~mol}^{-1}$ above the $E_{0}$ cited above for the MECP, and the pre-exponential factor is $2-3$ orders of magnitude smaller than typical for a simple bond fission reaction. ${ }^{40}$ This reflects the small probability for intersystem crossing. By analogy, for $\mathrm{N}_{2} \mathrm{~S}$ we therefore expect a high-pressure limiting $\mathrm{E}_{\mathrm{a}}$ of $\sim 145 \mathrm{~kJ} \mathrm{~mol}^{-1}$. Keeping the same pre-exponential factor for the high-pressure limit as for $\mathrm{N}_{2} \mathrm{O}$ decomposition would mean that, at $1000 \mathrm{~K}$ and $10 \mathrm{bar}$ of $\mathrm{N}_{2}$, the predicted first-order dissociation rate of $\mathrm{N}_{2} \mathrm{~S}$ is less than $6 \%$ of the highpressure limit.

An alternative estimate of when fall-off effects might become significant for reaction (1) can be made from the first study of $\mathrm{N}_{2} \mathrm{O}$ dissociation at the high-pressure limit by Olschewski et al. ${ }^{41}$ They showed that the kinetics do not reach the fall-off region until pressures of at least 10 bar. They also directly related $\mathrm{k}_{\infty}$ to the magnitude of the spin-orbit splitting in atomic oxygen. The greater spin-orbit coupling in sulfur as compared to oxygen means that the pre-exponential factor will be greater for $\mathrm{N}_{2} \mathrm{~S}$ than for $\mathrm{N}_{2} \mathrm{O}$ at the high-pressure limit, and so Eq. (6) is applicable at even higher pressures than 10 bar. Consistent with this idea, the study by Olschewski 
et $a l^{42}$ of $\mathrm{CO}_{2}$ and $\mathrm{CS}_{2}$ dissociation provides a preexponential factor for $\mathrm{k}_{\infty}$ which is an order of magnitude larger for the sulfur analog vs. the oxygen species.

\section{Combustion implications}

The analogy between the $\mathrm{S}+\mathrm{N}_{2}$ and $\mathrm{O}+\mathrm{N}_{2}$ reactions suggests that atomic sulfur may conceivably be active in formation of reactive nitrogen intermediates and subsequently nitric oxide under favorable conditions. The importance of $\mathrm{S}$ $+\mathrm{N}_{2}$ as an initiating step in formation of NO depends on the rate of the association reaction, as well as the lifetime of $\mathrm{N}_{2} \mathrm{~S}$ and the reactivity of $\mathrm{N}_{2} \mathrm{~S}$ towards the radical pool. Both the rate of the $S+N_{2}$ association and the lifetime $\tau$ of $\mathrm{N}_{2} \mathrm{~S}$ are between the corresponding values for the $\mathrm{N}_{2} \mathrm{O}$ and $\mathrm{NNH}$ mechanisms, i.e., $\mathrm{k}\left(\mathrm{O}+\mathrm{N}_{2}\right)<\mathrm{k}_{-1}<\mathrm{k}\left(\mathrm{H}+\mathrm{N}_{2}\right)$ and $\tau_{\mathrm{NNH}}$ $<\tau_{\mathrm{N}_{2} \mathrm{~S}}<\tau_{\mathrm{N}_{2} \mathrm{O}}$. Thus, in principle, nitrogen fixation via the reverse of reaction (1) is feasible.

To investigate this possibility in more detail, we have carried out chemical kinetic modeling for oxidation of a $\mathrm{CO} / \mathrm{H}_{2} / \mathrm{H}_{2} \mathrm{~S}$ mixture at $1800 \mathrm{~K}$ and 1 bar in a perfectly stirred reactor under conditions ranging from fuel-lean to fuel-rich. The $\mathrm{H}_{2} \mathrm{~S}$ inlet concentration was representative of the level encountered for volatile $\mathrm{S}$ in coal combustion, i.e., $1000 \mathrm{ppm}$, and a $\mathrm{CO} / \mathrm{H}_{2}$ mixture was selected as a fuel to avoid the complexities of hydrocarbon/sulfur interactions. The stirred reactor environment was chosen because this type of reactor augments the radical levels during combustion. The reaction mechanism was drawn from Glarborg, ${ }^{43}$ except for the $\mathrm{N}_{2} \mathrm{~S}$ subset, which was estimated in the present work. The following reactions were considered:

$$
\begin{gathered}
\mathrm{N}_{2} \mathrm{~S}+\mathrm{H} \rightarrow \mathrm{N}_{2}+\mathrm{SH}, \\
\mathrm{N}_{2} \mathrm{~S}+\mathrm{H} \rightarrow \mathrm{NS}+\mathrm{NH}, \\
\mathrm{N}_{2} \mathrm{~S}+\mathrm{O} \rightarrow \mathrm{N}_{2}+\mathrm{SO}, \\
\mathrm{N}_{2} \mathrm{~S}+\mathrm{O} \rightarrow \mathrm{NO}+\mathrm{SO}, \\
\mathrm{N}_{2} \mathrm{~S}+\mathrm{OH} \rightarrow \mathrm{N}_{2}+\text { HOS. }
\end{gathered}
$$

All of the reactions of $\mathrm{N}_{2} \mathrm{~S}$ were assumed to be very fast, with $\mathrm{k}_{7}=\mathrm{k}_{9}=\mathrm{k}_{10}=1.5 \times 10^{-10} \mathrm{~cm}^{3}$ molecule ${ }^{-1} \mathrm{~s}^{1}$, and $\mathrm{k}_{11}$ $=8 \times 10^{-11} \mathrm{~cm}^{3}$ molecule ${ }^{-1} \mathrm{~s}^{-1}$. Reaction (10) would provide a direct pathway from $\mathrm{N}_{2} \mathrm{~S}$ to $\mathrm{NO}$, similar to the $\mathrm{NNH}$ $+\mathrm{O} \rightarrow \mathrm{NH}+\mathrm{NO}$ process. The rate of reaction (8) was calculated from an estimate of the reverse step, as described below.

Selected modeling predictions are shown in Fig. 2. The calculations indicate that over the range of fuel-air equivalence ratios $0.7 \leq \mathrm{f} \leq 1.6$ and temperatures of $1500-1800 \mathrm{~K}$, the formation of $\mathrm{NO}$ from the $\mathrm{N}_{2} \mathrm{~S}$ mechanism is always well below $0.1 \mathrm{ppm}$, compared to levels of $\mathrm{NO}$ by other mechanisms of 3-12 ppm $(1500 \mathrm{~K})$ and $23-39 \mathrm{ppm}(1800 \mathrm{~K})$ in the present work. Nitric oxide is formed from $\mathrm{N}_{2} \mathrm{~S}$ by reaction with atomic oxygen (reaction (10)). The reason for the low impact of the $\mathrm{N}_{2} \mathrm{~S}$ mechanism is that the $\mathrm{S}$-atom concentration is always much lower than those of the $\mathrm{O} / \mathrm{H}$ radicals.

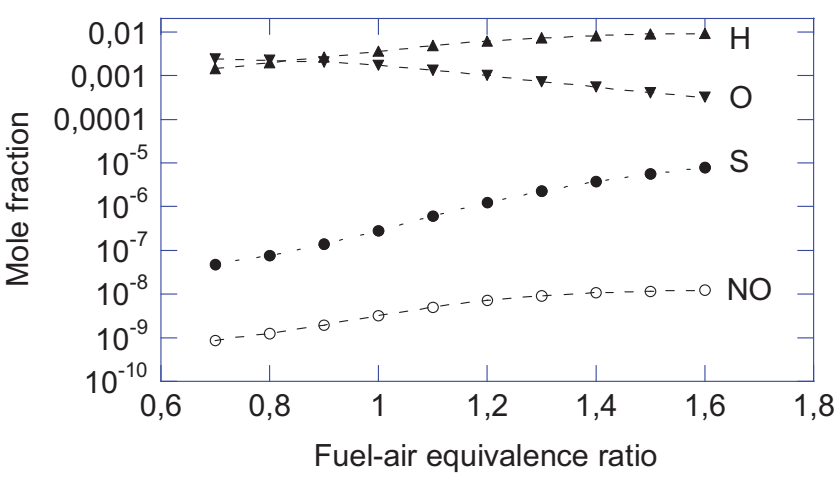

FIG. 2. Modeling predictions with a detailed reaction mechanism for formation of $\mathrm{NO}, \mathrm{H}, \mathrm{O}$, and $\mathrm{S}$ as function of fuel-air equivalence ratio in a perfectly stirred reactor at $1800 \mathrm{~K}$ and a nominal residence time of $0.1 \mathrm{~s}$. The fuel is $50 \% \mathrm{H}_{2}$ and $50 \% \mathrm{CO}$, burnt in air. Formation of $\mathrm{NO}$ through the $\mathrm{N}_{2} \mathrm{~S}$ intermediate is the only active $\mathrm{NO}$ formation mechanism in the model.

Under reducing conditions, where $[\mathrm{S}]$ peaks, the $[\mathrm{H}] /[\mathrm{O}]$ ratio is almost 100, and reaction (10) is insignificant compared to reaction (8). Under stoichiometric and lean conditions, where the rates of 7 and 10 become comparable in magnitude, the concentration of atomic $\mathrm{S}$ is small, 3-4 orders of magnitude lower than $[\mathrm{H}]$ and $[\mathrm{O}]$, and negligible amounts of $\mathrm{N}_{2} \mathrm{~S}$ are formed. Based on these calculations, the $\mathrm{N}_{2} \mathrm{~S}$ mechanism appears to be unimportant for forming $\mathrm{NO}$ from $\mathrm{N}_{2}$ in most combustion systems. A possible exception could be high temperature industrial processes with high sulfur concentrations, such as combustion of $\mathrm{H}_{2} \mathrm{~S}$ or the Claus process.

In addition to the formation through recombination of $S$ with $\mathrm{N}_{2}, \mathrm{~N}_{2} \mathrm{~S}$ may be formed from radical-radical reactions. By analogy to steps forming $\mathrm{N}_{2} \mathrm{O}$, we would expect the reactions between NS and either NH or NCO to be active:

$$
\begin{gathered}
\mathrm{NH}+\mathrm{NS} \rightarrow \mathrm{N}_{2} \mathrm{~S}+\mathrm{H}, \\
\mathrm{NCO}+\mathrm{NS} \rightarrow \mathrm{N}_{2} \mathrm{~S}+\mathrm{CO} .
\end{gathered}
$$

As a first estimate these steps would be expected to behave similarly to the analogous reactions involving $\mathrm{N}_{2} \mathrm{O}$. The NS radical has been detected in sulfur-seeded flames ${ }^{44}$ and reactions (8') and (12) may contribute to the conversion of reaction nitrogen species to $\mathrm{N}_{2}$. Observations from a very fuel-rich methane flame ${ }^{2 \mathrm{~b}}$ show that addition of $\mathrm{SO}_{2}$ accelerates the decay of NO in the post-flame zone. However, despite years of research, the direct interaction of nitrogen and sulfur species in flames is still controversial, and further work is desirable to identify the important steps.

\section{CONCLUSIONS}

The enthalpy of formation of singlet $\mathrm{N}_{2} \mathrm{~S}$ has been characterized by coupled cluster methods, along with the minimum energy crossing point between singlet and triplet potential energy curves as the $\mathrm{N}-\mathrm{S}$ distance is increased. The results are used to predict the kinetics of spin-forbidden $\mathrm{N}_{2} \mathrm{~S}$ decomposition to $\mathrm{N}_{2}+\mathrm{S}\left({ }^{3} \mathrm{P}\right)$ at the low-pressure limit. Modeling of high temperature $\mathrm{CO} / \mathrm{H}_{2}$ oxidation indicates that under stoichiometric and lean conditions the concentration of atomic sulfur is likely to be too small for $\mathrm{S}+\mathrm{N}_{2} \rightarrow \mathrm{N}_{2} \mathrm{~S}$ followed 
by $\mathrm{O}+\mathrm{N}_{2} \mathrm{~S} \rightarrow \mathrm{NO}+\mathrm{NS}$ to be a significant source of $\mathrm{NO}$, while under fuel-rich conditions the dominant path for $\mathrm{N}_{2} \mathrm{~S}$ consumption is via reaction with $\mathrm{H}$ atoms.

\section{ACKNOWLEDGMENTS}

P.M. thanks Professor Jürgen Troe for valuable discussions and the National Science Foundation (NSF) (Grant No. CBET-0756144), the R. A. Welch Foundation (Grant No. B-1174), and the UNT Faculty Research Fund for support. Computational facilities were purchased with NSF Grant No. CHE-0741936.

${ }^{1}$ J. A. Miller and C. T. Bowman, Prog. Energy Combust. Sci. 15, 287 (1989); P. Glarborg, A. D. Jensen, and J. E. Johnsson, ibid. 29, 89 (2003)

${ }^{2}$ (a) J. O. L. Wendt, Combust. Flame 25, 355 (1975); (b) J. O. L. Wendt, J. T. Morcomb, and T. L. Corley, Proc. Combust. Inst. 17, 671 (1979); (c) J. O. L. Wendt, E. C. Wottan, and T. L. Corley, Combust. Flame 49, 261 (1983); (d) T. L. Corley and J. O. L. Wendt, ibid. 58, 141 (1984); (e) S. I. Tseregounis and O. I. Smith, Combust. Sci. Technol. 30, 231 (1983); (f) A. T. Chen, P. C. Malte, and M. M. Thornton, Proc. Combust. Inst. 20, 769 (1984); (g) L. D. Pfefferle and S. W. Churchill, Ind. Eng. Chem. Res. 28, 1004 (1989); (h) W. Nimmo, E. Hampartsoumian, K. J. Hughes, and A. S. Tomlin, Proc. Combust. Inst. 27, 1419 (1998).

${ }^{3}$ C. Wentrup, S. Fischer, A. Maquestiau, and R. Flammang, J. Org. Chem. 51, 1908 (1986); R. D. Brown, P. S. Elmes, and D. McNaughton, J. Mol. Spectrosc. 140, 390 (1990); P. Kambouris, T.-K. Ha, and C. Wentrup, J. Phys. Chem. 96, 2065 (1992); P. Hassanzadeh and L. Andrews, J. Am. Chem. Soc. 114, 83 (1992).

${ }^{4}$ R. D. Davy and H. F. Schaefer III, J. Am. Chem. Soc. 113, 1917 (1991).

${ }^{5}$ C. L. Collins, Y. Yamaguchi, and H. F. Schaefer III, J. Chem. Phys. 98, 4777 (1993); A. T. Wong and G. B. Backsay, Chem. Phys. Lett. 217, 17 (1994).

${ }^{6}$ Y. Pak, R. C. Woods, and K. A. Peterson, J. Chem. Phys. 104, 7073 (1996).

${ }^{7}$ W. D. Breshears, J. Phys. Chem. 99, 12529 (1995); S. K. Ross, J. W. Sutherland, S.-C. Kuo, and R. B. Klemm, J. Phys. Chem. A 101, 1104 (1997).

${ }^{8}$ M. Röhrig, E. L. Petersen, D. F. Davidson, and R. K. Hanson, Int. J. Chem. Kinet. 28, 599 (1996).

${ }^{9}$ J. Troe, Ann. Rev. Phys. Chem. 29, 223 (1978).

${ }^{10}$ A. H. H. Chang and D. R. Yarkony, J. Chem. Phys. 99, 6824 (1993).

${ }^{11}$ H. Nakamura and S. Kato, J. Chem. Phys. 110, 9937 (1999); J. N. Harvey and M. Aschi, Phys. Chem. Chem. Phys. 1, 5555 (1999).

${ }^{12}$ D.-Y. Hwang and A. M. Mebel, Chem. Phys. 259, 89 (2000).

${ }^{13}$ K. Raghavachari, G. W. Trucks, J. A. Pople, and M. Head-Gordon, Chem. Phys. Lett. 157, 479 (1989).

${ }^{14}$ T. H. Dunning, Jr., K. A. Peterson, and A. K. Wilson, J. Chem. Phys. 114, 9244 (2001).
${ }^{15}$ T. H. Dunning, Jr, J. Chem. Phys. 90, 1007 (1989).

${ }^{16}$ R. A. Kendall, T. H. Dunning, Jr., and R. J. Harrison, J. Chem. Phys. 96, 6796 (1992).

${ }^{17}$ M. J. Frisch, G. W. Trucks, H. B. Schlegel et al., GAUSSIAN 03, Revision E.01, Gaussian, Inc., Pittsburgh, PA, 2003.

${ }^{18}$ MOLPRO, version 2006.1 and 2009.1 quantum chemistry package designed by H.-J. Werner and P. J. Knowles, R. Lindh, M. Schütz, P. Celani et al.

${ }^{19}$ P. J. Knowles, C. Hampel, and H.-J. Werner, J. Chem. Phys. 99, 5219 (1993).

${ }^{20}$ K. A. Peterson and T. H. Dunning, Jr., J. Chem. Phys. 117, 10548 (2002).

${ }^{21}$ R. D. Cowan and D. C. Griffin, J. Opt. Soc. Am. 66, 1010 (1976).

${ }^{22}$ C. E. Moore, Atomic Energy Levels, Vol. I (Hydrogen through Vanadium) (U.S. Government Printing Office, Washington, D.C., 1949).

${ }^{23}$ M. Kállay and P. R. Surján, J. Chem. Phys. 115, 2945 (2001).

${ }^{24}$ CFOUR, a quantum-chemical program package designed by J. F. Stanton and J. Gauss, version 1.0, M. E. Harding P. G. Szalay, A. A. Auer et al.; MOLECULE, integral package designed by J. Almlöf and P. R. Taylor; PROPS, integral package designed by P. R. Taylor; ABACUS, integral package designed by T. Helgaker, H. J. Aa. Jensen, P. Jørgensen, and J. Olsen; ECP routines designed by A. V. Mitin and C. van Wüllen.

${ }^{25}$ D. E. Woon and T. H. Dunning, Jr., J. Chem. Phys. 98, 1358 (1993).

${ }^{26}$ K. P. Huber and G. Herzberg, Constants of Diatomic Molecules (Van Nostrand Reinhold, New York, 1979).

${ }^{27}$ T. Helgaker, W. Klopper, H. Koch, and J. Noga, J. Chem. Phys. 106, 9639 (1997).

${ }^{28}$ D. Feller, J. Chem. Phys. 96, 6104 (1992).

${ }^{29}$ J. M. L. Martin, Chem. Phys. Lett. 259, 679 (1996).

${ }^{30}$ Thermodynamic Properties of Individual Substances, edited by L. V. Gurvich, I. V. Veyts, and C. B. Alcock (Hemisphere, New York, 1989).

${ }^{31}$ J. D. Cox, D. D. Wagman, and V. A. Medvedev, CODATA Key Values for Thermodynamics (Hemisphere, New York, 1989).

${ }^{32}$ B. Nagy, P. Szakács, J. Csontost, Z. Rolik, G. Tasi, and M. Kállay, J. Phys. Chem. A 115, 7823 (2011).

${ }^{33}$ W. C. Gardiner, Jr., Combustion Chemistry, 2nd ed. (Springer-Verlag, New York, 1999), Chap. 5.

${ }^{34}$ T. J. Lee and P. R. Taylor, Int. J. Quant. Chem. S23, 199 (1989).

${ }^{35}$ D. C. Astholz, K. Glanzer, and J. Troe, J. Chem. Phys. 70, 2409 (1979).

${ }^{36}$ J. Troe, J. Phys. Chem. 83, 114 (1979).

${ }^{37}$ H. Hippler, J. Troe, and H. J. Wendelken, J. Chem. Phys. 78, 6709 (1983).

${ }^{38}$ D. Woiki and P. Roth, Ber. Bunsenges. Phys. Chem. 96, 1347 (1992); M. Oya, H. Shiina, K. Tsuchiya, and H. Matsui, Bull. Chem. Soc. Jpn. 67, 2311 (1994).

${ }^{39}$ H. Endo, K. Glänzer, and J. Troe, J. Phys. Chem. 83, 2083 (1979).

${ }^{40}$ S. W. Benson, Thermochemical Kinetics, 2nd ed. (Wiley, New York, 1976).

${ }^{41}$ H. A. Olschewski, J. Troe, and H. G. Wagner, Ber. Bunsenges. Phys. Chem. 70, 450 (1966).

${ }^{42}$ H. A. Olschewski, J. Troe, and H. G. Wagner, Ber. Bunsenges. Phys. Chem. 70, 1060 (1966).

${ }^{43}$ P. Glarborg, Proc. Combust. Inst. 31, 77 (2007).

${ }^{44}$ J. B. Jeffries and D. R. Crosley, Combust. Flame 64, 55 (1986). 